\title{
Erratum to: The Value of Rain: Benefit-Cost Analysis of Rainwater Harvesting Systems
}

\author{
Suzanne Dallman ${ }^{1} \cdot$ Anita M. Chaudhry ${ }^{2}$. \\ Misgana K. Muleta ${ }^{3}$. Juneseok Lee ${ }^{4}$
}

Published online: 2 September 2017

(C) Springer Science+Business Media B.V. 2017

\section{Erratum to: Water Resour Manage (2016) 30:4415-4428 \\ https://doi.org/10.1007/s11269-016-1429-0}

Unfortunately the authors have discovered an error in the modified EPA SWMM model used as the basis for this research. The model was intended to calculate the amount of roof runoff captured during a rain event, estimate the amount used later for irrigation and/or indoor use, and refill the cistern during the next storm on a space-available basis. The model error caused miscalculation of space available in the cisterns during each rain event. This resulted in a significant over-estimation of the amount of potable water use displaced by the use of captured rainwater. Thus our conclusion that rainwater harvesting is cost-effective, based on a comparison with the cost of imported water, is actually incorrect. We sincerely regret the error.

Our assumptions in this research were very conservative on all fronts. We chose to use low water and energy values for the benefits side, which may have underestimated the true costs of imported water. We assumed retail prices for cisterns, although in practice these have typically been made available free or below retail cost to water customers by the water retailer, who can buy them in bulk for a much lower cost. We also assumed conservative scenarios for use of the captured rainwater, for example considering the time since the last rain and evapotranspiration rates, which do not necessarily reflect actual consumer behavior. We limited the benefits to the

The online version of the original article can be found at https://oi.org/10.1007/s11269-016-1429-0

Suzanne Dallman

suzanne.dallman@csulb.edu

1 Department of Geography, California State University Long Beach, 1250 Bellflower Blvd, Long Beach, CA 90840, USA

2 Department of Economics, California State University, Chico, Chico, CA 95929, USA

3 Department of Civil and Environmental Engineering, California Polytechnic State University, San Luis Obispo, CA 93407, USA

4 Department of Civil and Environmental Engineering, San José State University, San José, CA 95192, USA 
avoided cost of imported water provided to customers, cost of energy used for pumping, and the value of reduced carbon emissions. We did not consider other benefits such as the reduction in surface runoff and reduced pollution loads carried to receiving waters. We are currently revising our scenarios to consider a more nuanced set of costs and benefits to determine under what conditions implementing rainwater harvesting might be a costeffective policy. 